\title{
Performance Assessment of a Triangular Integrated Collector Using Neural Networks
}

\author{
Omer K. Ahmed ${ }^{1}$, Raid W. Daoud ${ }^{1 *}$, Ruaa H. Ali Al-Mallah ${ }^{2}$ \\ ${ }^{1}$ Department of Electrical Techniques, Al-Hawija Technical Institute, Northern Technical University, Mosul, Iraq, ${ }^{2}$ Department of Computer \\ Engineering Techniques, Faculty of Technical College/Mosul, Northern Technical University, Mosul, Iraq
}

\section{${ }^{*}$ Corresponding author: \\ Raid W. Daoud, \\ Department of Electrical \\ Techniques, Al-Hawija \\ Technical Institute, Northern \\ Technical University, Mosul, \\ Iraq. \\ E-mail: raid_hwj@ntu.edu.iq}

Received: 12 September 2019

Accepted: 16 June 2020

Published: 30 June 2020

DOI

10.25156/pti.v10n1y2020.pp175-181

\section{A B S T R A C T}

A numerical study is achieved on a new shape of temperature saver solar collector using an artificial neural network. The storage collector is a triangle face and a right triangle pyramid for the volumetric shape. It is obtained by cutting a cube from one upper corner at $45^{\circ}$, down to the opposite hypotenuse of the base of the cube. The numerical study was carried out using the computational fluid dynamics code (ANSYS-Fluent) software with natural convection phenomenon in the pyramid enclosure. Elman backpropagation network is used for his ability to find the nearest solution with the smallest error rate. The network consists of three layers, each of different corresponding weights. The results show that the temperature and velocity distributions throughout the operating period were obtained. The influence of introducing an internal partition inside the triangular storage collector was investigated. Also the optimum geometry and location for this partition were obtained. The enhancement was best at $y=0.25 \mathrm{~m}$, whereas the height of triangular collector was $0.5 \mathrm{~m}$. The hourly system performance was evaluated for all test conditions. The performance of the NN to train a model for this work was 0.000207 , while the error of the calculation was $1 \times 10-2$ as average.

Keywords: Assessment; Collector; Optimization; Storage; Triangular

\section{INTRODUCTION}

The expense of delivering star gatherers is two hundred $\$$ per sq. meter Adeyanju (2013. p. 68), Ahmed and Ahmed (2011. p. 38), and Ahmed (2017. p. 363). The high starting quality is the first drawback to wind up a standard for the human, it is the decided of this examination to build up infrequent esteem, solid, and affordable solar radiator framework for local use Ahmed and Mohammed (2017. p. 115). That is means the upgrading of renewable energy has been done for the solar rather than wind and other sources. All the traditional star radiator frameworks contain two primary segments; the authority and furthermore the vessel. Joudi (1990. p. 109) brief a swap stockpiling reflector for residential bind give and furthermore the authority was imaginary just from the unremarkably out there business materials exploitation simple apparatuses and methodology. The upside of the brief gather style is that it is utilized for water stockpiling to switch the standard cubic or round and hollow storage unremarkably utilized in Iraqi homes. Ahmed (2018. p. 252) investigated logically and by experimentation, the vibe of a conservative reflector. Inside the brief style, the authority and furthermore the reservoir is reduced into one surrender water stream brought about by thermosyphon activity. The execution of a substitution model of the capacity reflector was researched numerically by Joudi et al. (2004. p. 394). The ANSYS programming bundle was used for this appraisal. In addition, Ahmed (2018. p. 255) considered numerically and by experimentation, the execution of a tube-shaped reduced gatherer in urban focus town.

The innovation incorporates a building style invented by cutting a 3D shape structure tank at entirely unexpected introductions. Amid this style, the best point of tendency is $10^{\circ}$ to $15^{\circ}$ over the scope edge to accumulate the elective vitality inside the winter season. The scope plot for city is $31^{\circ}$, capital of Iraq is $33^{\circ}$, and city is $36^{\circ}$. Subsequently, for straightforwardness and solidarity, a $45^{\circ}$ normal point of tendency would be suitable Ahmed and Bawa (2018. p. 5). The measure of the gather is control exploitation very surprising measurements for the base and stature in the meantime. To expand the retention of elective vitality, the sun struck surface has been painted dark. The sun struck surface is painted dark to broaden elective vitality ingestion. A glass sheet or the other clear materials is wont to cowl the inclined viewpoint that is confronting the sun and each 
one the contrary sides are protected exploitation warm insulation Ahmed and Bawa (2018. p. 16).

The present work solves the control to contemplate numerically, in three measurements, the impact of some operational parameters on the execution of the triangular stockpiling gatherer appeared in Figure 1. The artificial neural network is used in this paper to optimize the solar collector parameters according to the current situation.

\section{NUMERICAL MODEL}

The Boussinesq estimate, whereby the liquid is thought to be Newtonian and compressible, implies the liquid thickness is dismantled as consistent from the effect of the thickness variety in assembling light powers. The thickness is accepted to differ exclusively with a temperature somewhat from a reference value Al-Nimr et al. (2018. p. 304). With these presumptions, the light impacts, normal with the expectation of complimentary convection, zone unit encased as body powers inside the energy conditions. The smooth movement is thought to be liminal inferable from appallingly low speed among the capacity, three dimensional, no inward warmth age, and for accommodation, the outcomes of radiation and gooey vitality dissemination territory unit disregarded. With these presumptions, the essential convection conditions are Henry and Malalasekera (2007. p. 127).

1. Continuity equation:

$$
\frac{\partial u}{\partial t}+\frac{\partial u}{\partial x}+\frac{\partial v}{\partial y}+\frac{\partial w}{\partial z}=0
$$

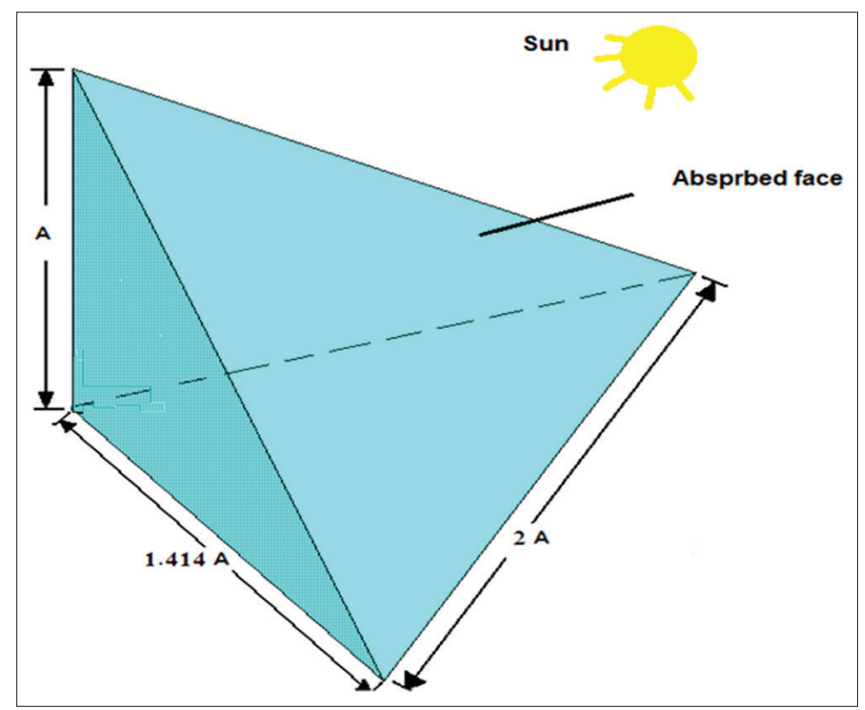

Figure 1: Schematic diagram of the triangular storage collector
2. Momentum equations:

$$
\begin{gathered}
\frac{\partial u}{\partial t}+u \frac{\partial u}{\partial x}+v \frac{\partial u}{\partial y}+w \frac{\partial u}{\partial z}=-\frac{1}{\rho} \frac{\partial p}{\partial x} \\
+v\left[\frac{\partial^{2} u}{\partial x^{2}}+\frac{\partial^{2} u}{\partial y^{2}}+\frac{\partial^{2} u}{\partial z^{2}}\right] \\
\frac{\partial v}{\partial t}+u \frac{\partial v}{\partial x}+v \frac{\partial v}{\partial y}+w \frac{\partial v}{\partial z}=-\frac{1}{\rho} \frac{\partial p}{\partial y}+g \beta\left(T-T_{o}\right) \\
+v\left[\frac{\partial^{2} v}{\partial x^{2}}+\frac{\partial^{2} v}{\partial y^{2}}+\frac{\partial^{2} v}{\partial z^{2}}\right] \\
\frac{\partial w}{\partial t}+u \frac{\partial w}{\partial x}+v \frac{\partial w}{\partial y}+w \frac{\partial w}{\partial z}=-\frac{1}{\rho} \frac{\partial p}{\partial z} \\
+v\left[\frac{\partial^{2} w}{\partial x^{2}}+\frac{\partial^{2} w}{\partial y^{2}}+\frac{\partial^{2} w}{\partial z^{2}}\right]
\end{gathered}
$$

3. Energy equation:

$$
\begin{aligned}
& \frac{\partial T}{\partial t}+u \frac{\partial T}{\partial x}+v \frac{\partial T}{\partial y}+w \frac{\partial T}{\partial z} \\
& =\frac{K}{\rho^{*} C_{p}}\left[\frac{\partial^{2} T}{\partial x^{2}}+\frac{\partial^{2} T}{\partial y^{2}}+\frac{\partial^{2} T}{\partial z^{2}}\right]
\end{aligned}
$$

In the finite volume method, the above equations are treated in a balanced form for finite-sized control volumes (CV). Equations 1, 2, and 3 can be re-written as:

$$
\begin{aligned}
& \frac{\partial(\rho \varphi)}{\partial t}+\frac{\partial(\rho u \varphi)}{\partial x}+\frac{\partial(\rho v \varphi)}{\partial y}+\frac{\partial(\rho w \varphi)}{\partial z} \\
& =\frac{\partial}{\partial x}\left(\Gamma \frac{\partial \varphi}{\partial x}\right)+\frac{\partial}{\partial y}\left(\Gamma \frac{\partial \varphi}{\partial y}\right)+\frac{\partial}{\partial z}\left(\Gamma \frac{\partial \varphi}{\partial z}\right)+S
\end{aligned}
$$

The fully implicit discretization equation for a typical control volume is shown as follows:

$$
\begin{aligned}
& a_{P} \varphi_{P}=a_{W} \varphi_{W}+a_{E} \varphi_{E}+a_{S} \varphi_{S}+a_{N} \varphi_{N} \\
& +a_{B} \varphi_{B}+a_{T} \varphi_{T}+a_{P}^{0} \varphi_{P}^{0}+S_{u}
\end{aligned}
$$

Re-write the above equations in the following terms:

$$
\frac{\partial(\rho \varphi)}{\partial t}+\operatorname{div}(\rho \varphi u)=\operatorname{div}(\Gamma \operatorname{grad}(\varphi))+S
$$

The capacity sun oriented gatherer complex geometry requires computational liquid elements approach. Standard connections of warmth exchange cannot be enough to depict the normal convection inside the sun 
oriented capacity collector Al-Nimr et al. (2018. p. 306). A business bundle of computational fluid dynamic (Familiar) was utilized to show the authority in this examination with the use of Gambit programming for work age. The triangular gatherer matrix was worked as in Figure 2. Amid this model, tetrahedral part kind was picked utilizing a lily-white issue solver with a certain plan. The second request subject was want to unravel the force and vitality equations Rahman et al. (2011. p. 50). Lightness driven stream is thought as normal convection stream and furthermore the Boussinesq guess is utilized for thickness. The discretization of the body power weighted subject is normally prescribed to determine high John William Strutt assortment streams. Therefore, the body power weighted topic was upheld to discretize the weight term ANSYS (2013). Weight verifiable with the cacophonic of administrators (PISO) algorithmic program that is normally prescribed for transient stream estimation was want to achieve the weight speed coupling. To manage the variable changes and keep away from disparity of arrangements all through arranged emphases, under-unwinding factors were connected. When goals of conditions, the ordinarily under-unwinding parameter esteems utilized were generally 0.3 and 0.7 for weight and force, severally, and 0.8 for every vitality and density Mohammed et al. (2018. p. 117).

\section{NEURAL NETWORK IMPLIMENTATION}

The NN is used in this work as a prediction model to discover the main temperature which must be reached for the given parameters (time and size). The Elman backpropagation network is used for his ability to find the nearest solution with the smallest error rate. The network

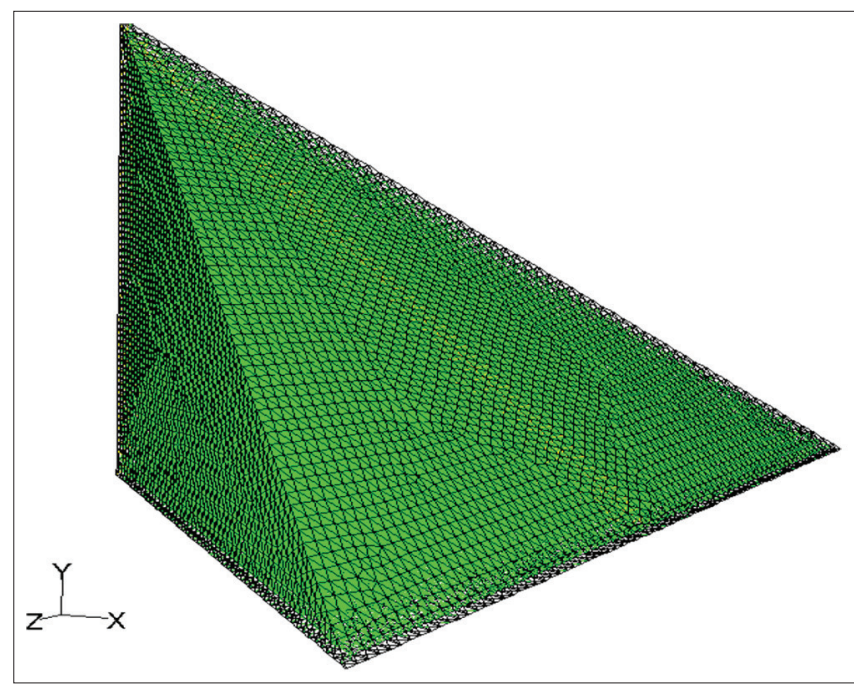

Figure 2: Mesh model of the triangular collector shown in Figure 3 represents the three layers with the corresponding weights.

\section{RESULTS AND DISCUSSION}

The hourly incident solar radiation on a tiled surface for 365 days was obtained by a computer program developed in this work based on the ASHRAE clear sky model Henry and Malalasekera (2007. p. 152), Shukla et al. (2013. p. 178). The volume of the triangular collector is $41.667 \mathrm{l}$ and the sunlit area is $0.353 \mathrm{~m}^{2}$ at a height (A) of $0.5 \mathrm{~m}$. All outcomes were assessed for commonplace winter days (thirteenth, fourteenth, fifteenth, and sixteenth of November). The hourly incident solar radiation on a tilted surface for 365 days was obtained by a computer program developed in this work based on the ASHRAE clear sky model Ben Slama (2012. p. 69). The volume of the triangular collector is 41.6671 and the sunlit area is $0.353 \mathrm{~m}^{2}$ at a height (A) of $0.5 \mathrm{~m}$. All outcomes were assessed for average winter days $\left(13^{\text {th }}, 14^{\text {th }}, 15^{\text {th }}\right.$, and $16^{\text {th }}$ of November).

\section{Effect of Collector Volume}

Figure 4 shows the relationship between the mean storage temperature and the heights of the collector. A varying

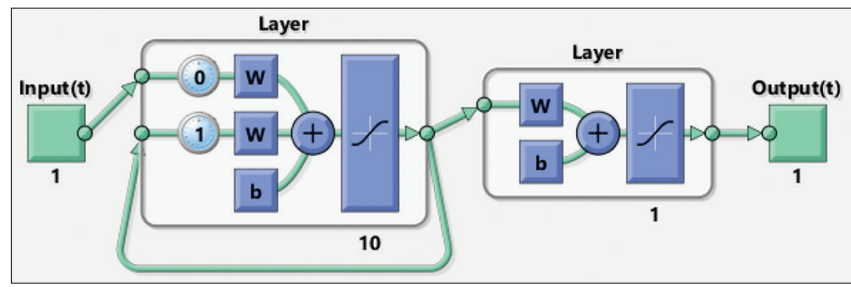

Figure 3: Elman network with the I/P, hidden, and O/P layer

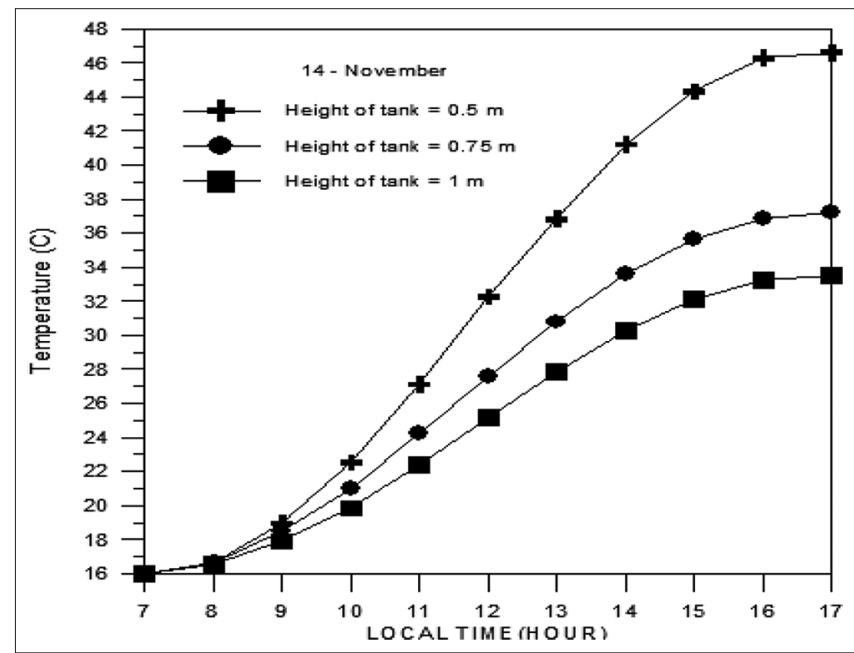

Figure 4: Variation of mean storage temperature for various volumes 


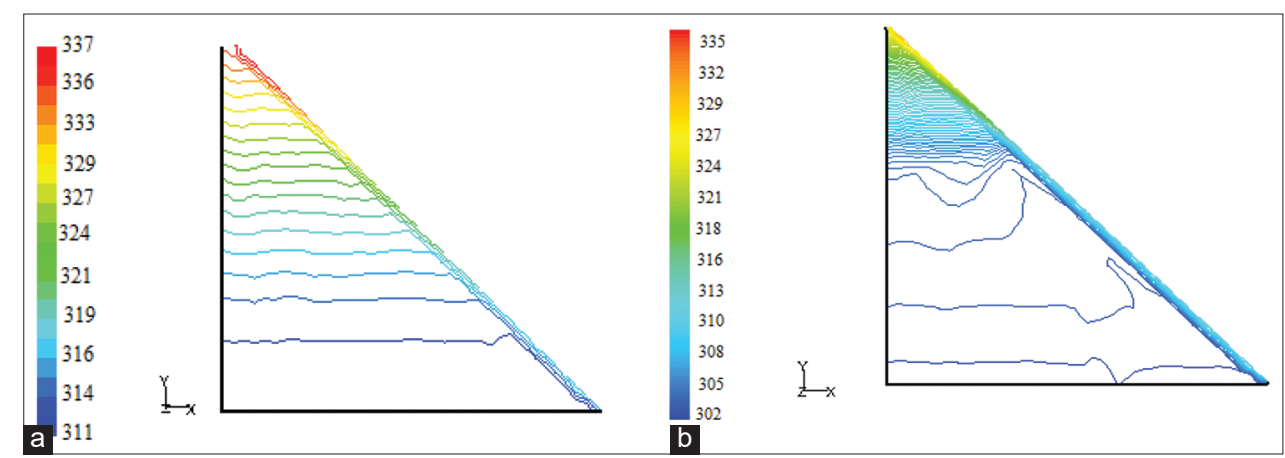

Figure 5: Storage water stratification inside the triangular collector. (a) Isothermal temperature lines at symmetry plane $A-A$ for $A=0.5 \mathrm{~m}$. (b) Isothermal temperature lines at symmetry plane $A-A$ for $A=1 \mathrm{~m}$

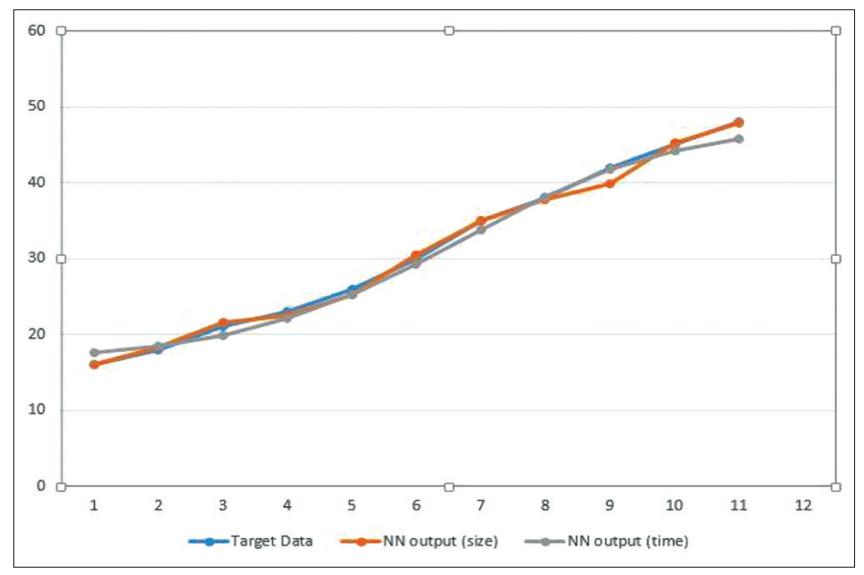

Figure 6: The NN response with respect to size and temp

height and base dimensions render varying storage volumes. It is observed that the mean storage temperature decreased with increasing volume Chaabane et al. (2014. p. 899). It is observed that the mean storage temperature reaches its maximum value at $\mathrm{A}=0.5 \mathrm{~m}$, where the collector volume is $41.67 \mathrm{l}$. The minimum is obtained for a collector with $\mathrm{A}=1 \mathrm{~m}$, where the collector volume is $333.33 \mathrm{l}$. Furthermore, the result predictions show that the stratified behavior of the collector becomes weaker with increasing volume, as shown in Figure 5.

The NN output satisfies the numerical conditions and its response exactly same as the conventional values, as shown in Figure 6. The three curves shown in Figure 5 represent the NN response with respect to collector size and time, as mentioned in the figure graph and legend. The curves have a big similarity which means a very error rate within the NN computation. The system performance and validation accuracy were fixed during the training process which is shown in Figure 7. The validation represents the optimized solution that can be fixed to obtain on the best system efficiency.

The agreement between the numerical predictions and the experimental data is good up to 2 p.m., as shown in

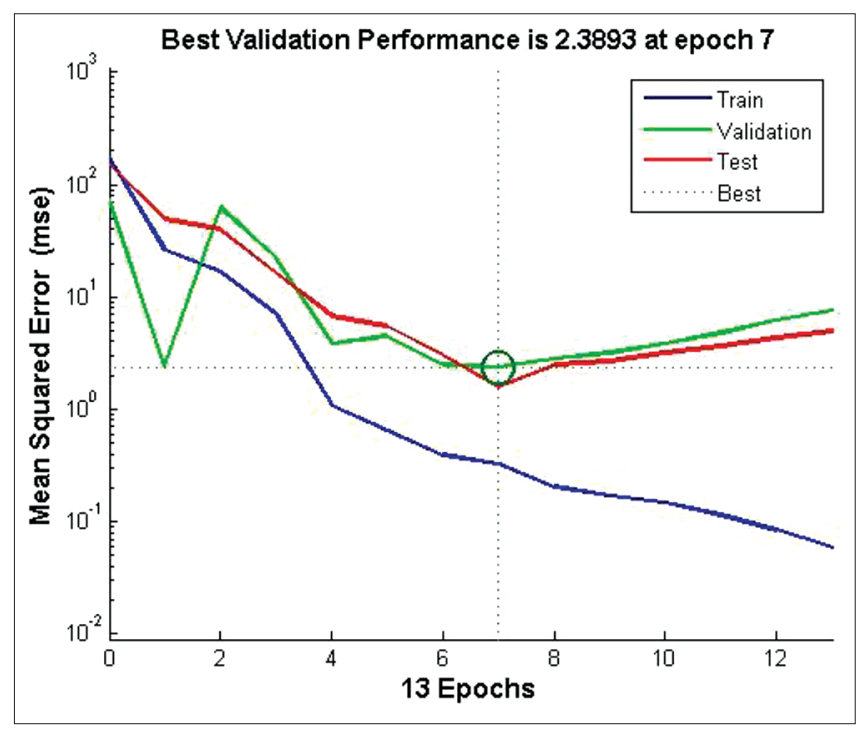

Figure 7: The NN train, test, and validation process and point of solution

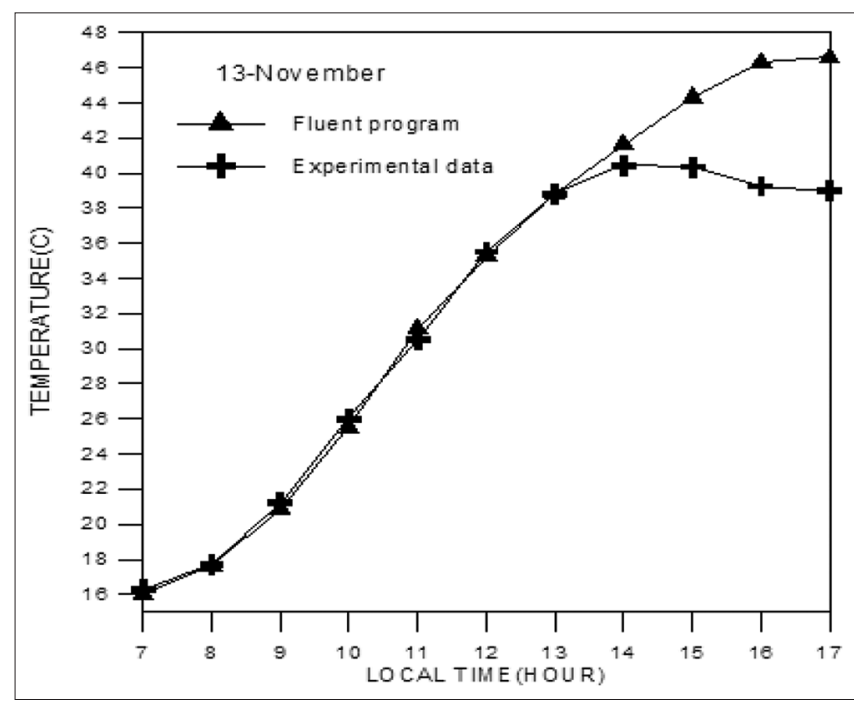

Figure 8: Numerical and experimental variation of the mean storage temperature

Figure 8. Furthermore, it is noted that a larger volume means the water capacity increases, and hence the storage 


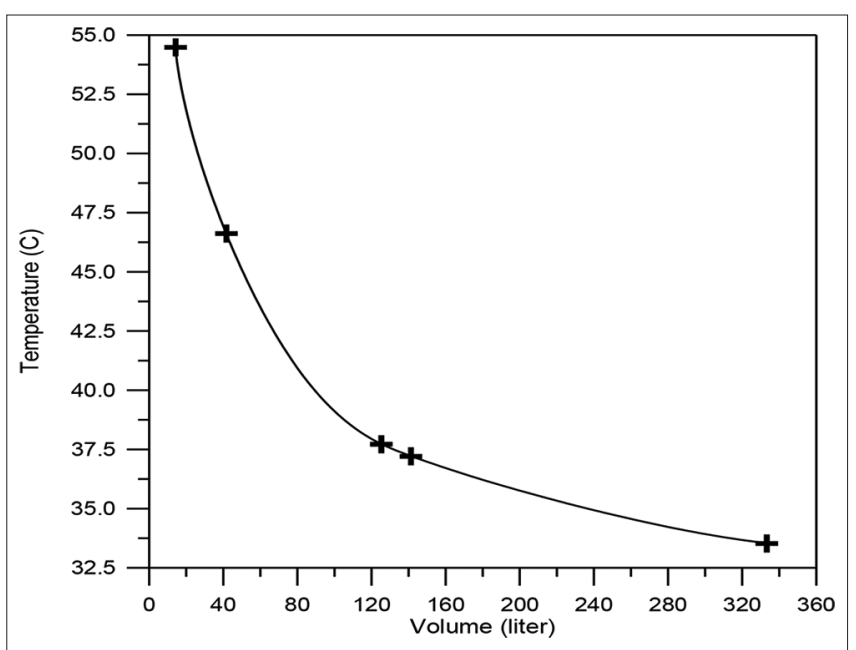

Figure 9: The relationship between the mean storage temperature and the collector volume

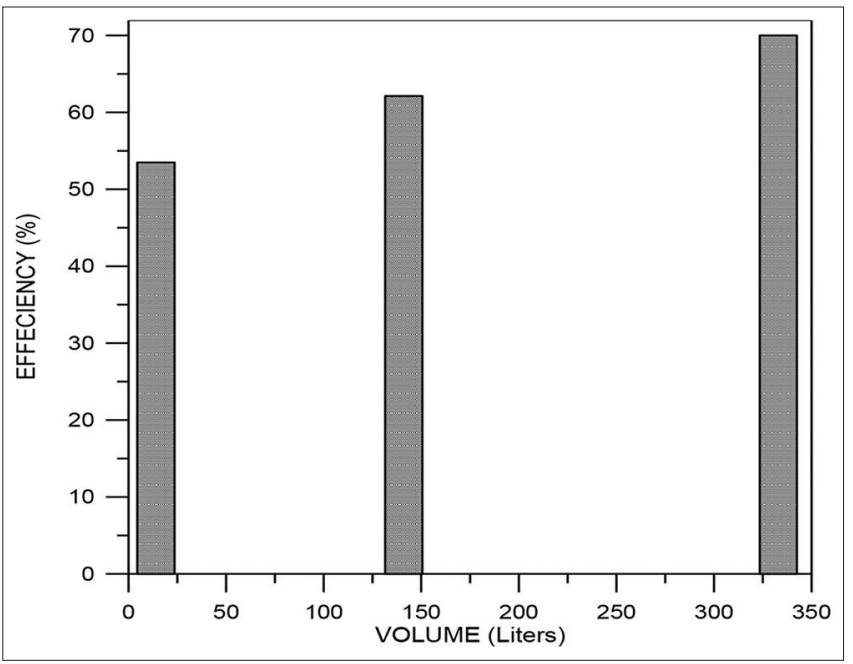

Figure 10: The relationship between overall efficiency and the collector volume

water temperatures at the end of day decreases and vice versa, Figure 9.

It is interesting to note that as the volume increases the collection efficiency increases because the thermal losses of the outside air decrease as shown in Figure 10.

\section{Effect of the Internal Partition}

It was suggested to investigate the influence of using an internal partition inside the collector and study its influence on the temperature distribution and collector performance. This was done using an internal partition with certain heights positioned in different locations, as shown in Figure 11, giving four different cases. All tests were carried out for a typical cold day.

The mean storage temperature will be used as a criterion for assessment. It is observed that when the partition is in a position which separates the collector into two equal volumes as in cases 2 and 3, there is no clear effect of the partition on the storage water temperature, as shown in Figure 12. The influence of the internal barrier is pronounced in cases 1 and 4, whereby an increase in the mean storage temperature is obtained. The separation between hot and cold water causes this increase. It is noticed in Figure 12 that the mean storage temperature for case (1) reaches $49^{\circ} \mathrm{C}$, which is higher than for other cases.

Figure 13 shows the effect of the barrier on the maximum temperature at the top of the collector. As shown, the maximum temperature was at 2 p.m. and reduced at the end of the operation period Mozumder (2013. p. 115).

Figure 14 shows the temperature distribution of water in a triangular tank at 3 p.m. for typical cold weather. The parcel of the case (1) ruins direct flow among warm and cold liquid, which is a valuable bring about situating the chilly water delta and the heated water outlet. Likewise, it demonstrates that fundamentally at no heap condition, the virus water is bound beneath the segment while the warm water is over the hindrance. It is seen that the temperature contrast between the top and base of the authority expanded altogether as contrasted and the no segment case. In addition, the stratification in authority was not bothered by the presence of the adiabatic partition Varghese and Manjunath (2017, p. 93).

\section{Effect of Nocturnal Cooling on Triangular Collector Performance}

The cozy contact between the capacity liquid and the safeguard plate in the capacity gatherer encourages effective sun oriented change yet can likewise prompt generous warmth misfortunes amid times of low and additionally zero sun based radiation, especially during the evening. Convective warmth trade with the encompassing air and transmitted warmth exchange to the chilly night sky are the huge systems of warmth misfortunes. This impact can be diminished, somewhat, by covering the straightforward essence of the framework by a removable protecting spread, for example, stopper of $50 \mathrm{~mm}$ thickness. It tends to be evacuated from the get-go in the following day with the goal that the water stays warm until the following morning. The dynamic reaction of the framework amid such cooling hours was examined by doing the transient investigation of the framework and completing the accompanying tests:

1. Transient examination without a protecting spread

2. Transient examination with a protecting spread.

In test 2, it was expected that the gatherer was secured by protection at 5 p.m. Furthermore, it was 


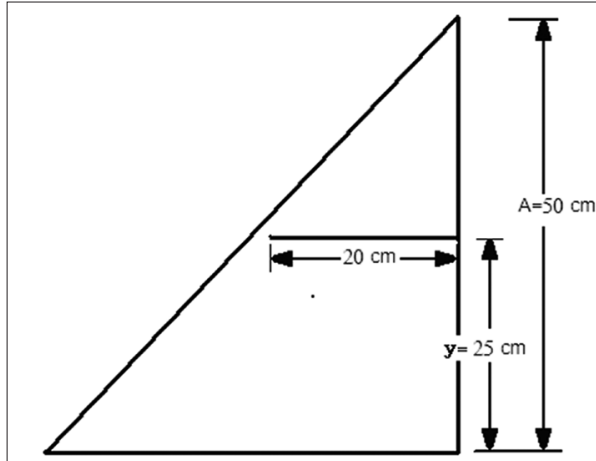

Case (1)

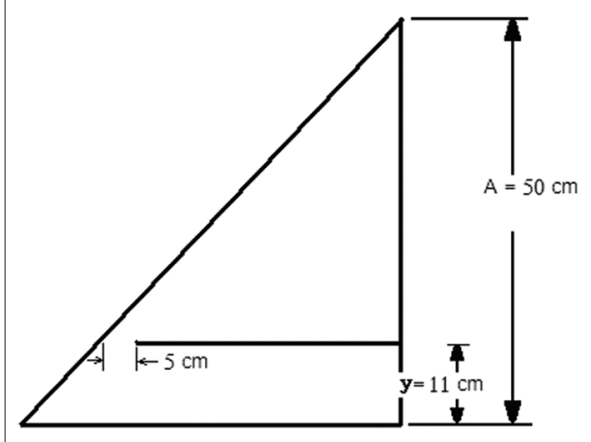

Case (3)

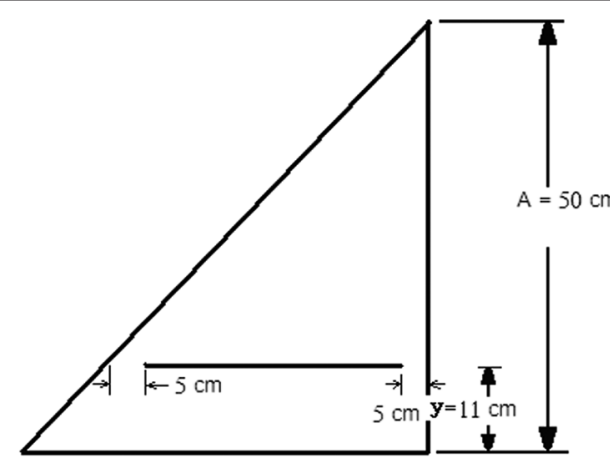

Case (2)

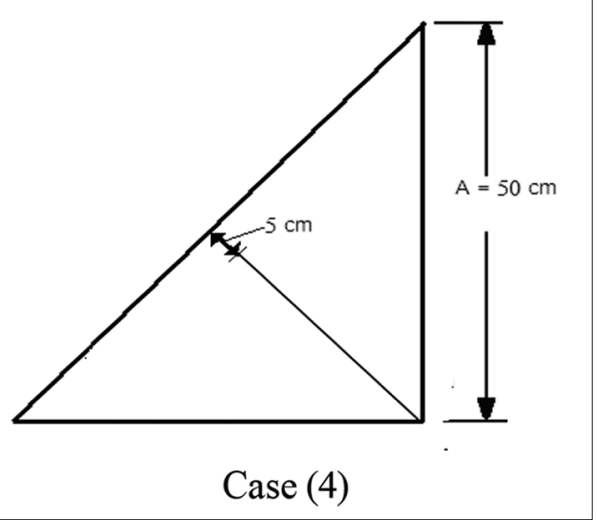

Figure 11: The various locations of partitions

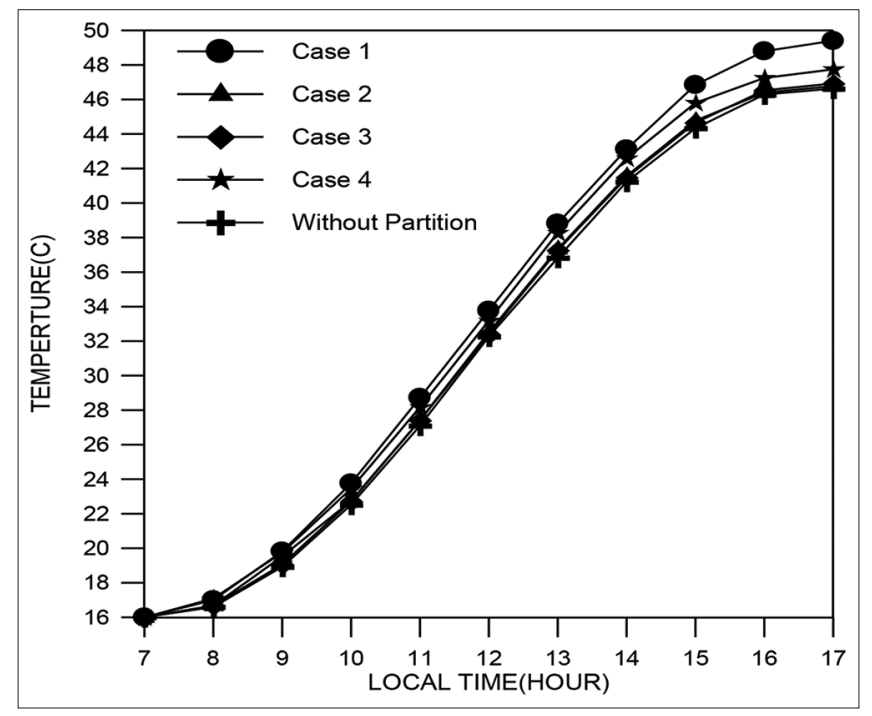

Figure 12: The barrier effect on the mean storage temperature

evacuated following day at around 7 a.m. amid test 1 , it was expected that the front face was with no spread. Water temperature ascends to $46.6,37.25$, and $33.5^{\circ} \mathrm{C}$ separately for 41, 141, and 333 , at around 5 p.m. toward the evening.

Yet, when this authority is secured with the protection of $5 \mathrm{~mm}$ thickness, the water temperature tumbles to 44.1,

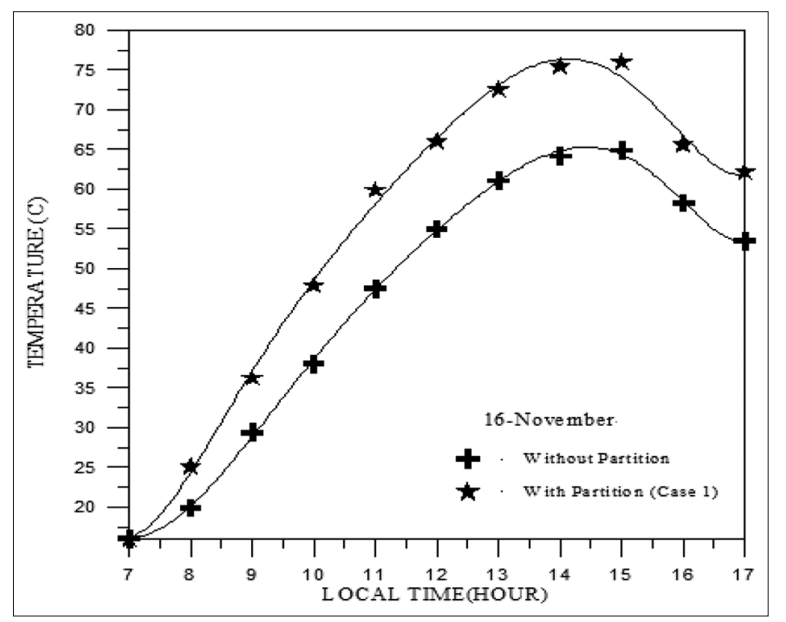

Figure 13: Effect the effect of partition on the max temperature in case 1

Table 1: Effect of natural cooling on mean storage temperature in the next morning

\begin{tabular}{lcc}
\hline $\begin{array}{l}\text { Collector volume } \\
\text { (liters) }\end{array}$ & \multicolumn{2}{c}{ Mean storage temperature $\left({ }^{\circ} \mathrm{C}\right)$} \\
\cline { 2 - 3 } & Without cover $\left({ }^{\circ} \mathrm{C}\right)$ & With cover $\left({ }^{\circ} \mathrm{C}\right)$ \\
\hline 41 & 34.8 & 44.1 \\
141 & 32.9 & 35.9 \\
333 & 30.6 & 32.67 \\
\hline
\end{tabular}

35.9, and $32.67^{\circ} \mathrm{C}$ separately, as in Table 1. It implies that the fall in water temperatures which were 11.83, 


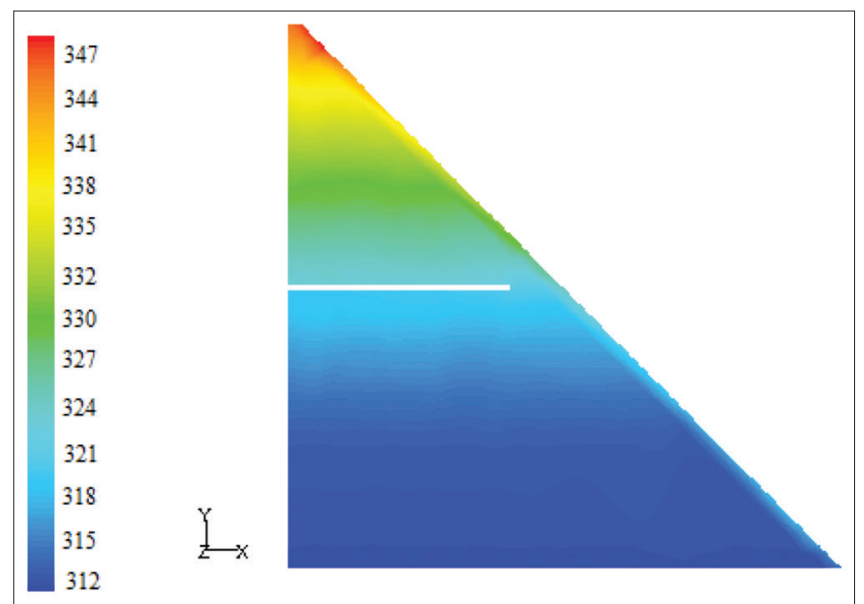

Figure 14: The effect of partition on temperature distribution (K) in a symmetry plane for case 1

4.32 , and $2.9^{\circ} \mathrm{C}$ has been decreased to $2.55,1.3$, and $0.87^{\circ} \mathrm{C}$, separately. The decrease in warmth misfortunes is a component of the volume of the authority. Since the decline of water temperature is little for the situation, have 141 and 333 liters volumes of the authority, at that point, the utilization of protection spread is not very promising Michael and Goic (2015. p. 85).

\section{CONCLUSIONS}

From the acquired outcomes, we can close the accompanying notes can be watched:

1. The nearness of an even obstruction inside the triangular stockpiling gatherer expands stratification of water and renders a higher mean stockpiling temperature. The upgrade was best at $\mathrm{y}=0.5 \mathrm{~m}$. The mean stockpiling temperature for case (1) comes to $49^{\circ} \mathrm{C}$, which is higher than for different cases

2. Stratification conduct reduces with expanding volume on the grounds that the violent impact starts to show up

3. Covering the sunlit zone of the framework with protection amid evening time improves the execution. Water temperature ascends to $46.6,37.25$, and $33.5^{\circ} \mathrm{C}$ individually for 41, 141, and $333 \mathrm{l}$, at around 5 p.m. toward the evening. This temperature tumbles to 34.8 , 32.9 , and $30.6^{\circ} \mathrm{C}$ in the following morning when these frameworks are left revealed amid evening time

4. Test and approval for the framework conduct gives a major unwavering quality amid the NN and fulfilling the traditional conditions.

\section{REFERENCES}

Adeyanju, A. A. 2013. Economic analysis of combined packed bed energy storage and solar collector system. Int. J. Renew. Energy
Res. 3(4): 2.

Ahmed, O. K. 2017. Experimental and numerical investigation of cylindrical storage collector (case study), Case Stud. Therm. Eng. 10: 362-369.

Ahmed, O. K. 2018. Assessment of the performance for a new design of storage solar collector. Int. J. Renew. Energy Res. 8(1): 250-257.

Ahmed, O. K. and A. H. Ahmed. 2011. Principles of Renewable Energies. $1^{\text {st }}$ ed. Foundation of Technical Education, Baghdad.

Ahmed, O. K. and S. M. Bawa. 2018. Reflective mirrors effect on the performance of the hybrid PV/thermal water collector. Energy Sustain. Dev. 43: 235-246.

Ahmed, O. K. and S. M. Bawa. 2018. The combined effect of nanofluid and reflective mirrors on the performance of $\mathrm{PV} /$ thermal solar collector. Therm. Sci. 21(3): 1-16.

Ahmed, O. K. and Z. A. Mohammed. 2017. Dust effect on the performance of the hybrid PV/thermal collector, Therm. Sci. Eng. Prog. 3: 114-122.

Ahmed, O. K. and Z. A. Mohammed. 2017. Influence of porous media on the performance of hybrid PV/thermal collector. Renew. Energy. 112: 378-387.

Al-Nimr, M. A., I. A. Al-Darawsheh and L. A. Al-Khalayleh. 2018. A novel hybrid cavity solar thermal collector. Renew. Energy. 115: 299-307.

ANSYS. 2013. ANSYS Fluent Tutorial Guide. ANSYS, Canonsburg.

Ben Slama, R. 2012. Experimentation of a plane solar integrated collector storage water heater. Energy Power Eng. 4: 67-76.

Chaabane, M., H. Mhiri and P. Bournot. 2014. Thermal performance of an integrated collector storage solar water heater (ICSSWH) with phase change materials (PCM). Energy Convers. Manag. 78: 897-903.

Henry, K. V. and W. Malalasekera. 2007. Introduction to Computational Fluid Dynamics. $2^{\text {nd }}$ ed. Pearson, Harlow.

Joudi, K. A., I. A. Hussein and A. A. Farhan. 2004. Computational model for a prism shaped storage solar collector with a right triangular cross section. Energy Convers. Manag. 45(3): 391409.

Michael, J. J. and R. Goic. 2015. Flat plate solar photovoltaic-thermal (PV/T) systems: A reference guide, Renew. Sustain. Energy Rev. 51: 62-88.

Mohammed, F., O. Khalil and A. Emad. 2018. Effect of climate and design parameters on the temperature distribution of a room. J. Build Eng. 17(2): 115-124.

Mozumder, A. 2013. An integrated collector storage solar water heater and study of its temperature stratification. Open J. Appl. Sci. 3: 112-115.

Rahman, M. M., M. M. Billah, N. N. Rahim, R. S. Amin and M. Hasanuzzaman. 2011. A numerical model for the simulation of double-diffusive natural convection in a triangular solar collector. Int. J. Renew. Energy Res. 1: 50-54.

Shukla, R., K. Sumathy, P. Erickson and J. Gong. 2013. Recent advances in the solar water heating systems: A review. Renew. Sustain. Energy Rev. 19: 173-190.

Varghese, J. and K. Manjunath. 2017. Experimental investigation and comparison between an integrated compound parabolic domestic solar water heater with and without an air gap introduced at the arms of the CPC. Int. J. Adv. Res. Innov. 5(1): 90-93. 